\title{
A methodic way to more sustainable farming systems
}

\section{P. VEREIJKEN}

DLO-Centre for Agrobiological Research, P.O. Box 14, NL 6700 AA Wageningen, Netherlands

Received 5 February 1991; accepted 29 August 1991

\begin{abstract}
A methodic pathway is suggested for the definition, elaboration, evaluation and introduction of farming systems based on an 'integrated' or an 'ecosystem-oriented' vision, both considered more sustainable than a 'world-market-oriented' vision. The objectives of these three basic types of systems are defined in measurable terms with respect to the major social values or interests supported or adversely influenced by agriculture. For each type of systems, a strategy is assessed through which the objectives can be achieved while avoiding their conflicts. Arable farming is taken as an example of the elaboration, evaluation and introduction of integrated and ecosystem-oriented systems. It is discussed how prototype systems can be developed on an experimental farm, evaluated by a pilot group of farmers and dispersed on a large scale. For the short term it is recommended to focus research and policy on integrated farming systems, as an urgently needed compromise between socio-economical and socioecological interests. For the long term it is recommended to develop ecosystem-oriented farming systems to solve the agricultural crisis in a more comprehensive and sustainable way.

Keywords: world-market-oriented, integrated, ecological farming systems, food, employment and basic income, environment, nature and landscape, health and well-being, mineral balances, fertilizers, organic manure, IPM, pesticides, crop rotation, agro-ecosystems.
\end{abstract}

\section{Introduction}

All over the world, agriculture is still being intensified, causing destabilisation of agro-ecosystems and environmental pollution. In developing countries it is understandable for various reasons, especially in those countries where food production can hardly keep pace with population increase. In industrialized countries it is absurd when one considers the growing surpluses of agricultural products, the decreasing income and employment in most rural areas and the growing concern of the consumers about the quality of their food. Fortunately, there is also a growing awareness that these immense problems cannot be solved one by one on an ad-hoc basis, but that a more comprehensive and sustainable vision of agriculture is needed. As a result, several new visions have been proposed, such as sustainable (Allen \& Van Dusen, 1988; Edwards et al., 1990), integrated (Vereijken \& Royle, 1989) and alternative agriculture (National Research Council of USA, 1989). However, their use is limited because they are hardly defined in measurable terms, elaborated into concrete farm- 


\section{P. VEREIJKEN}

Table 1. Methodic pathway for definition, elaboration, evaluation and introduction of more sustainable farming systems.

\section{Quantitative definition of objectives}

$1.1 \quad$ Values and parameters identify the social values or interests supported or adversely influenced by agriculture in the area and identify the parameters to quantify the major effects.

1.2 Objectives

define the objectives of a more sustainable system in terms of those values and parameters.

\section{Elaboration}

2.1 Strategy

formulate an overall strategy to achieve the objectives of the system while avoiding conflicts.

2.2 Methods and techniques

identify the essential components of the system and state to what extent they are already operational or need further research.

2.3 Development of prototypes

compose and develop one or more prototypes of the system on an experimental farm until the results indicate it has/they have become viable.

3 Evaluation and optimization test and improve the prototype(s) with a pilot group of farmers to obtain safe and generally applicable variants of the farming system.

4 General introduction

mobilize extension and education and provide for the information they and the farmers need to adopt the system.

ing systems and tested for feasibility. Therefore, a methodic pathway is suggested for the stepwise definition, elaboration, evaluation and introduction of more sustainable farming systems (Table 1).

\section{Quantitative definition of objectives}

Theoretically, an infinite number of agricultural visions are possible. However, two extreme visions of agriculture seem to limit the scale in practice.

\section{World-market-oriented vision}

In this vision agriculture is the production of plant and animal commodities aimed at maximising profit. It should be minimally regulated, protected or subsidised by national and international laws and agreements.

This vision is increasingly dominating current agriculture, stimulated by a global trend toward liberalizing trade. 


\section{Ecosystem-oriented vision}

In this vision agriculture is the management of agro-ecosystems* aimed at sufficient and sustainable supply of the home-market with food and other nature products. It should be based on knowledge of, and respect and responsibility for, the biosphere, and supported by national and international laws and agreements.

Since both visions have their strong and weak points, a pragmatic vision can be proposed as an intermediate solution.

\section{Integrated vision}

In this vision agriculture is an industry aimed at optimally serving all social values and interests involved.

In Table 2 the major values and interests involved are listed together with appropriate parameters. The objectives of the three basic farming visions are quantitatively expressed in these parameters. This quantification is still in general terms and should be done in more detail, depending on the agricultural activities and regions to be considered, in conformity with policy plans for the short and long term. Such a quantitative definition is an indispensable frame of reference for a consistent elaboration and a comprehensive evaluation of more sustainable systems.

\section{Elaboration of farming systems}

\section{Overall strategy}

Once the objectives are quantitatively defined, an overall strategy should be formulated to avoid conflicts of the objectives (Table 1, step 2.1). Table 3 ranks the objectives of the three basic visions. It clearly shows the opposite priorities of the market- and ecosystem-oriented visions and the intermediate position of the integrated vision.

An overall strategy for world-market-oriented farming can be simply formulated as striving for the greatest difference between yields and costs, taking into account legal constraints. However, two major conflicts of objectives should be faced. One is between profit and employment, the other between profit and nature/environment. The primary cause of these conflicts is the interaction between the free market and technology leaving farmers no other choice than to intensify production in order to remain competitive (Figure 1). Supporters of world-market-oriented agriculture consider loss of employment as inevitable and hope to overcome environmental problems by technological adaptations and innovations. However, there is serious doubt about the willingness of the community to continue to accept the social and environmental costs of a world-market-oriented agriculture.

\footnotetext{
* An ecosystem is a unity in time and space of a community of plants and animals in interaction with each other and their abiotic environment (forest, lake, mountain range etc.). Agro-ecosystems are dominated by man and his foodplants and -animals (field, farm, region etc.).
} 


\section{P. VEREIJKEN}

Table 2. General matrix for definition, elaboration and evaluation of farming visions and systems.

\begin{tabular}{|c|c|c|c|c|c|}
\hline \multirow{2}{*}{\multicolumn{2}{|c|}{$\begin{array}{l}\text { Social values } \\
\text { or interests } \\
\text { involved }\end{array}$}} & \multirow[t]{3}{*}{ Parameters } & \multicolumn{3}{|c|}{ Objectives of the 3 basic visions $^{1}$} \\
\hline & & & $\begin{array}{l}\text { world-market } \\
\text { oriented }\end{array}$ & integrated & $\begin{array}{l}\text { ecosystem- } \\
\text { oriented }\end{array}$ \\
\hline \multirow{7}{*}{$\begin{array}{l}1 \\
1.1 \\
1.2\end{array}$} & Food supply & & & & \\
\hline & quantity & food/person in energy equivalents & - & WHO & WHO \\
\hline & quality & & & & \\
\hline & - nutritional value & $\begin{array}{l}\text { composition of single products in relation } \\
\text { to a daily diet }\end{array}$ & - & WHO & WHO \\
\hline & $\begin{array}{l}\text { - harmful compounds } \\
\text { and micro-organisms }\end{array}$ & $\begin{array}{l}\text { content of single products in relation to a } \\
\text { daily diet }\end{array}$ & $\mathrm{L}$ & $\geqslant \mathrm{L}$ & $>\mathbf{L}$ \\
\hline & - taste & appreciation by taste pannels & $\mathbf{S}$ & $\mathrm{S}$ & $S$ \\
\hline & $\begin{array}{l}\text { - appearance and } \\
\text { suitability for } \\
\text { preservation and } \\
\text { processing }\end{array}$ & $\begin{array}{l}\text { various commercial and industrial } \\
\text { standards of single products }\end{array}$ & $\mathrm{S}$ & $\mathrm{S}$ & $S$ \\
\hline 1.3 & stability & $\begin{array}{l}\text { variation in yields }\left(\mathrm{kg} \mathrm{ha}^{-1}\right) \text { in relation to } \\
\text { (inter)national food stocks }\end{array}$ & $\mathrm{L}$ & $\mathrm{L}$ & $\mathrm{L}$ and $\mathrm{FAO}$ \\
\hline \multirow[t]{5}{*}{1.4} & sustainability & & & & \\
\hline & - soil fertility & $\begin{array}{l}\text { content of air, water, nutrients, org. matter } \\
\text { input/output of dry and organic matter }\end{array}$ & $\begin{array}{l}S \\
-\end{array}$ & $\begin{array}{l}S \\
\geqslant 1\end{array}$ & $\begin{array}{l}S \\
\geqslant 1\end{array}$ \\
\hline & - climate & input/output of $\mathrm{CO}_{2}$ & - & $\max$ & $\max$. and $>1$ \\
\hline & - non-renewable & input (non-solar)/output of energy & - & $\min$. & $\min$. and $<1$ \\
\hline & resources & input/output of phosphorus & - & 1 & 1 \\
\hline 1.5 & accessibility & $\begin{array}{l}\text { prices of single products in relation } \\
\text { to a daily diet }\end{array}$ & $\mathrm{L}$ & $\mathrm{L}$ & $\mathrm{S}^{2}$ \\
\hline 2 & Employment & & & & \\
\hline 2.1 & at farm level & full-time workers/farm & $\min$. & $\geqslant 1$ & $\geqslant 1$ \\
\hline 2.2 & $\begin{array}{l}\text { at regional and } \\
\text { national level }\end{array}$ & $\begin{array}{l}\text { full-timers in agriculture and related } \\
\text { industries and services }\end{array}$ & - & $\mathrm{S}$ & $S$ \\
\hline \multirow[t]{3}{*}{3} & Basic income and profit & & & & \\
\hline & at farm, regional & income/hired worker & $\mathrm{L}$ & $\geqslant \mathrm{L}$ & $\geqslant \mathrm{L}$ \\
\hline & and national level & income/entrepreneur & $\max$ & $\max$ & $\begin{array}{l}\geqslant \mathrm{L} \text { hired } \\
\text { worker }\end{array}$ \\
\hline 4 & Abiotic environment & emissions/ha of: & & & \\
\hline 4.1 & soil & $\begin{array}{l}\text { persistent and accumulating compounds } \\
\text { such as heavy metals and pesticides }\end{array}$ & $\mathrm{L}$ & $\geqslant \mathrm{L}$ & $>\mathbf{L}$ \\
\hline 4.2 & air & $\begin{array}{l}\text { volatile compounds such as } \mathrm{NH}_{3} \text { and } \\
\text { certain pesticides }\end{array}$ & $\mathbf{L}$ & $\geqslant \mathrm{L}$ & $>\mathrm{L}$ \\
\hline 4.3 & $\begin{array}{l}\text { shallow and ground } \\
\text { waters }\end{array}$ & $\begin{array}{l}\text { mobile and persistent compounds such } \\
\text { as nutrients and pesticides }\end{array}$ & $\mathrm{L}$ & $\geqslant \mathrm{L}$ & $>\mathbf{L}$ \\
\hline 5 & Nature and landscape & & & & \\
\hline 5.1 & flora and fauna & various indices of diversity & $-3^{3}$ & $\max .^{4}$ & $\max ^{4}$ \\
\hline \multirow[t]{2}{*}{5.2} & landscape & nature and culture historical uniqueness & - & $\mathrm{S}$ & $\mathrm{S}$ \\
\hline & & $\begin{array}{l}\text { functionalism (agriculture, nature } \\
\text { recreation etc.) }\end{array}$ & $\mathrm{L}$ & $\mathrm{S}$ & $S$ \\
\hline 6 & Health and well-being & & & & \\
\hline 6.1 & $\begin{array}{l}\text { health and well-being } \\
\text { of animals }\end{array}$ & $\begin{array}{l}\text { veterinary and ethological } \\
\text { parameters }\end{array}$ & $\mathrm{L}$ & $\geqslant \mathrm{L}$ & $>\mathbf{L}$ \\
\hline 6.2 & $\begin{array}{l}\text { health and well-being } \\
\text { of humans }\end{array}$ & medical and sociopsychological parameters & $\mathrm{L}$ & $\geqslant \mathrm{L}$ & $>\mathbf{L}$ \\
\hline
\end{tabular}

\footnotetext{
${ }^{1}$ Objectives: WHO and FAO is norms of the United Nations, stated by World Health Organization and Food and Agriculture Organiation. (>) L and $\mathrm{S}$ is (better than) (inter)national Legal or System-specific norms towards certain values. Max. and min. is effort for maximal or minimal quantity or effect.

${ }^{2}$ Prices of products from ecosystem-oriented farming have to be higher than those of market-oriented farming, but a wholesome diet based on ecoproducts does not necessarily have to cost more than a conventional diet.

${ }^{3}$ Nature and landscape conservation are separated from agriculture.

${ }^{4}$ Nature and landscape conservation are integrated with agriculture.
} 
Table 3. Priorities of the three basic farming visions with respect to the basic values and interests involved in agriculture.

\begin{tabular}{lccc}
\hline Values/interests & World-market-oriented & Integrated & $\begin{array}{l}\text { Ecosystem-orien- } \\
\text { ted }^{1}\end{array}$ \\
1 Food supply & & & +++ \\
2 Employment and basic income & + & ++ & +++ \\
3 Profit & + & ++ & +++ \\
4 Abiotic environment & + & ++ & +++ \\
5 Nature and landscape & + & ++ & +++ \\
6 Health and well-being & + & ++ & +++
\end{tabular}

${ }^{1}$ Ecosystem-oriented agriculture starts from the responsibility of society as a whole. The rural population is responsible for a sustainable and multi-functional management of the agro-ecosystems as reflected in certified quality products. The urban population is responsible for an acceptable standard of living for the rural population by paying appropriate prices for the certified products. As a result, quality of both urban and rural life has higher priority than profit.

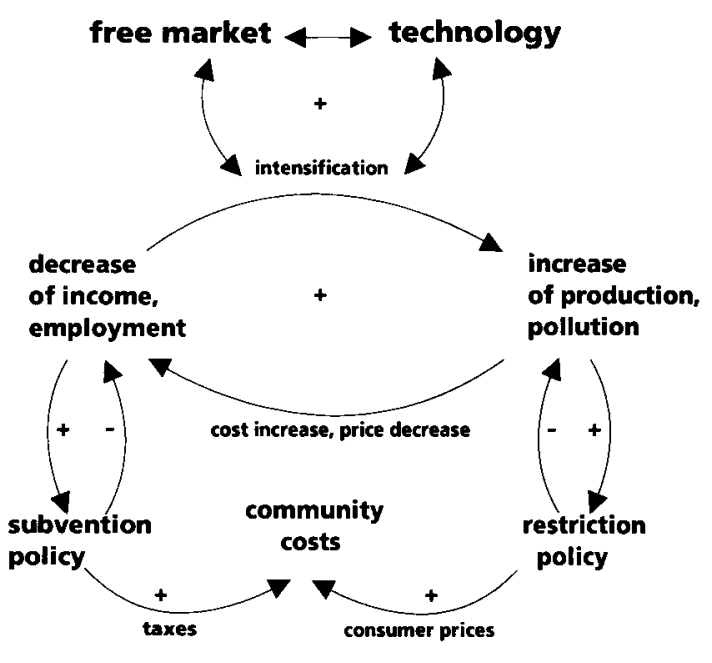

Fig. 1. The agricultural crisis as a kind of 'perpetuum mobile', suggesting sustainability will never be achieved unless the primary vicious circle is broken by a market system based on social consensus between producers and consumers to control technology and save the biosphere.

An overall strategy for integrated farming systems could be a multiple-goal approach that includes the following:

1. Changing from greater production to cost reduction and the improvement of quality of both products and production methods through substituting expensive and/ or potentially noxious inputs, such as fertilizers, pesticides and hormones/antibiotics, by both agricultural and ecological knowledge, labour and non-chemical husbandry techniques.

2. Encouragement and conservation of flora and fauna on and around farms to stabi- 


\section{P. VEREIJKEN}

lize the agro-ecosystem as a major preventive measure against outbreaks of pests, weeds and diseases.

The main advantages of this integrated farming strategy, would according to Figure 1 be:

a. Less pressure on employment/income and profit of the farmers at increasing cost of production, and decreasing prices of products caused by a world-market-oriented policy.

b. Less pollution of the environment, so more safety for public health and nature/ landscape.

The success of this strategy is still in question, since integrated systems still are scarce. It can be expected to alleviate the environmental problems (El Titi, 1989; Haeni, 1989; Vereijken, 1989a), but whether it can also help to maintain employment is rather doubtful. Therefore integrated systems should be considered rather as a compromise for the short term. An overall strategy for ecosystem-oriented farming would be to strive for a consistent integration of all objectives involved, especially through a complete substitution of the potentially noxious inputs mentioned above. It would imply a higher priority for employment, environment, nature/landscape and health/well-being, but it could conflict with food supply and income/profit. Supporters of ecosystem-oriented farming hope to overcome a possible lack of (affordable) food by better production techniques and an energy-efficient, minimally processed and principally vegetarian diet. The income/profit objectives should be ensured through sufficient prices for the farm products sold under a label of certified quality (Figure 1). Recently, several authors have reported on ecological (or organic) farming in practice, concluding that yields may still be lower but incomes/profits are generally comparable with conventional farming, because consumers are increasingly willing to pay premium prices for products of multi-dimensional quality (National Research Council of USA, 1989). Therefore, it seems justified to consider ecosystem-oriented farming as the most promising concept to attain a comprehensive and sustainable solution of the agricultural crisis.

\section{Methods and techniques}

Once the objectives are quantified and an overall strategy defined, the next methodic step to more sustainable farming systems is the development of appropriate methods and techniques (Table 1, step 2.2). It requires a concerted action of the various disciplines, which is harder to achieve the more the disciplines are subdivided and institutionalized. Mostly, the maximum achievable is concerted action of relevant (sub)disciplines on separate system components. Such a decentralized model of cooperation may eventually lead to a consistent set of methods and techniques, if it is based on a consistent set of sub-strategies. This can be demonstrated by the major components of integrated arable farming systems (Table 4, step 1). These may also be considered as the major components of ecological farming systems, provided artificial fertilizers and pesticides are substituted by appropriate (combinations of) components, such as organic manure, biological $\mathrm{N}$-fixation, crop rotation, resistant varieties and mechanical weed control. 
Table 4. Methodic steps at the elaboration, evaluation and introduction of integrated arable farming systems, as being taken in the Netherlands.

1 Disciplinary institutes develop the methods and techniques of integrated farming systems in a coordinated way.

1.1 Environmentally safe methods of maintaining soil fertility

1.2 Varieties with broad resistance, sufficient productivity and high quality.

1.3 Biological and physical methods of crop protection with chemicals as last resort, as far as allowed.

1.4 Equipment, machines and buildings for a technically optimum management.

1.5 Cropping systems aimed at quality and profitability.

2 Experimental stations coordinate the composition and development of prototype systems on regional experimental farms (Wijnands \& Vereijken, 1992):

- experimental farms on representative locations in specific growing areas. For example, in the Netherlands, Nagele in the central clay district (1979); Veendam in the peaty sand district (1986); and Vredepeel in the light sand district (1989). These three farms cover the need of Dutch development of soil type specific prototype systems in a reasonable way.

3 Research and extension introduce and test the prototype systems on a small scale (Wijnands, 1992).

3.1 Regional formation of pilot groups of farmers for planned conversion from conventional to integrated farming.

3.2 Technical, economic and environmental progress is monitored and evaluated (feedback to steps $1+2$ ).

3.3 Major input/output relations are optimized to obtain generally usable cropping and farming systems.

4 Extension and education introduce integrated production systems on a large scale (Wijnands, 1992).

4.1 Manuals and courses for extension specialists and teachers.

4.2 Adaptation of subject-matter in agricultural schools.

4.3 Courses and study groups for farmers.

4.4 Appropriate cropping manuals and viewdata.

Environmentally safe methods of maintaining soil fertility. In current, increasingly world-market-oriented farming, physical soil fertility is usually restored by means of cultivation between two subsequent crops. Soil is also cultivated to control weeds and to incorporate animal and green manure. Minimum tillage is often used or proposed for erosion control and cost reduction of labour and machines. However, it may also increase weeds and volunteer plants and therefore the need of herbicides. By contrast, in integrated and ecological farming soil fertility should first of all be maintained by a multi-functional crop rotation based on the following demands (Figure 2):

1. Crops reducing physical and chemical soil fertility (lifted crops with low input of organic matter, such as potato and sugar-beet) must be alternated with crops restoring soil fertility (mowed crops with large root systems and high inputs of organic matter, such as cereals, grasses and legumes).

2. Cropping frequency of single crops or groups of related crops must be limited to maintain a balanced soil life, with plant-parasitic organisms well below economic damage thresholds. 


\begin{tabular}{l}
$\begin{array}{l}\text { maintenance of } \\
\text { soil fertility }\end{array}$ \\
\hline $\begin{array}{l}\text { current } \\
\text { integrated/ } \\
\text { ecological }\end{array}$ \\
water/air supply etc.) \\
- crop rotation \\
- organic manure \\
- green manure \\
- tillage \\
chemically (nutrient \\
supply and -recycling) \\
- organic manure \\
- N-fixing crops \\
- green manure \\
fertilizers \\
biologically (stress by \\
harmful species) \\
- crop rotation \\
resistant varieties \\
- tillage (weed control) \\
- pesticides
\end{tabular}

Fig. 2. Opposite strategies of current ('market-oriented') and integrated/ecological farming systems based on whether or not substituting a multi-functional crop rotation and organic inputs by physical and chemical inputs and support energy.

3. Cropping sequences in time and space should be based on minimum negative interactions and maximum positive interactions with respect to structure and stability of soils, supply and recovery of nutrients and occurrence of diseases, pests and weeds.

The net economic output of sophisticated integrated or ecological rotations would be seriously underestimated by simple calculations based on current costs and yields of the separate crops. In long-term research on complete farming systems, the actual economic results are mostly surprisingly more favourable compared to current world-market-oriented systems (El Titi, 1989; El Titi \& Landes, 1990; Haeni, 1989; Vereijken, 1989a, 1990a). In industrialized countries, chemical soil fertility is mostly maintained routinely through high inputs of organic and inorganic fertilizers without much regard to nutrient losses and their adverse effects on environment and nature. Advice based on soil analysis may reduce overdosage, but mostly remains aimed at maximum crop yields protected by routine sprays of pesticides, since high inputs of $\mathrm{N}$ fertilizers are known to stimulate diseases, pests and weeds (Jordan et al., 1989; Daamen et al., 1989). Moreover, high $\mathrm{N}$ inputs may endanger the quality of fresh 


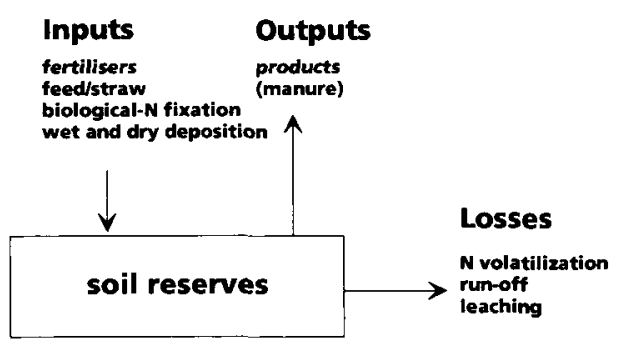

* Mutation of soil reserves $=$ inputs - outputs - losses

Fig. 3. Balance* sheet of the nutrient flows in agro-ecosystems (field, farm, region, etc.) as a basis of Integrated Nutrient Management.

products such as vegetables because of too high content of nitrate, too low content of dry matter, less suitability for processing and preservation etc. In order to avoid these adverse effects, a strategy of Integrated Nutrient Management (INM) based on the following demands (Figure 3) is suggested:

1. Chemical soil fertility must be maintained at an appropriate level, not too low for a quantitatively good yield and not too high for vital crops with a low need of pesticides and a qualitatively good yield.

2. Dosage and application of the nutrients must lead to a maximum utilization by the crops and to minimum losses into the environment.

3. Fertilizers must be substituted as much as possible by animal and green manure for several reasons:

- improvement and maintenance of soil fertility, physical (structure), chemical (plant nutrition) and biological (resistance against pests and diseases);

- cost reduction and yield increase;

- saving of non-renewable resources, especially of support energy ( $N$ fertilizer production) and $\mathrm{P}$;

- better balance between inputs and outputs of nutrients and consequently less pressure on environment and nature, especially for farms or regions with intensive animal production based on high inputs of feed stuffs.

From a synthesis of these demands, an INM farm strategy has been developed and tested, in which animal manure covers the $\mathrm{P}$ needs fully and $\mathrm{K}$ and $\mathrm{N}$ needs as much as possible. The manure is applied with minimum losses of $\mathrm{NH}_{3}$ and $\mathrm{NO}_{3}$ (Vereijken, 1990b). In conclusion, soil fertility in integrated and ecological systems is first of all to be maintained by a multi-functional crop rotation and Integrated Nutrient Management. Soil tillage should not stand on its own, but should support these two major instruments as appropriate.

Varieties with broad resistance, sufficient productivity and high quality. Resistance of crops to major local pests and diseases and competitivity of crops to weeds is the best basis for their health, together with a multifunctional crop rotation. Until now breeding has emphasised higher production capacity. Breeding for resistance has 


\section{P. VEREIJKEN}

received lower priority because of less demand, due to perceived economic returns. As a result, it was necessary to intensify chemical plant protection. Therefore it should be recommended strongly to plant breeders that priority should be shifted from yield increase to disease resistance and product quality. In order to encourage this, minimum criteria should be laid down for the submission of new and the maintenance of established cultivars. For example, if this is done for the current lists of Dutch winter wheat and potato cultivars, it appears that none can completely fulfil the demands on disease resistance and quality (Vereijken, 1989b; Vereijken \& Van Loon, 1991). Finally it is recommended that cultivars are examined in future within a context of integrated or ecological cropping including a low or even no input of fertilizers and pesticides.

Integrated methods of crop protection. Primarily, control of pests, diseases and weeds should be based on biological and physical methods. Chemical control is to be considered as a last resort in integrated systems (Vereijken, 1989c). It should be limited to pesticides which fulfil the highest demands of public health and environmental protection. For a more efficient use of pesticides, better guidelines have to be developed, based on crop observations, damage forecasts and cost-benefit analysis. Automated guidance systems could be useful in this respect. Until now a supervised control system for cereal diseases called EPIPRE had been one of the few successes in this field (Zadoks, 1988). Similar guided systems should be developed for supervised control of other major pests, such as potato blight.

Appropriate machines and equipment. A general objection to current mechanization is that it is too expensive and too heavy. More attention should be given to the development of light, energy- and soil-conserving machines. Other issues concern the application of fertilizers and pesticides. Current spreaders of mineral fertilizers and organic manure are too variable both in length and width of spread. Slurry should be injected into the soil or ploughed under immediately to avoid volatilization of ammonia. Inputs of active pesticide ingredients can be strongly reduced by better spraying equipment and techniques. Also in the field of mechanical weed control, improvements are still possible, through better collaboration between engineers, agronomists, weed specialists, and farmers.

Cropping systems aimed at quality and profitability. Mostly, cropping programs are based on partial knowledge from factorial experiments. In these experiments more than three cropping variables are rarely studied and yield is the major crop parameter assessed. As a result, interactions between major cropping variables are overlooked and underestimated and the highest physical yield will seldom coincide with the highest possible difference between total returns and allocated costs. Therefore it is recommended that cropping programmes are developed from experiments using complete cropping systems, with sensible combinations of soil cultivation, fertilization, choice of cultivar, sowing technique and crop protection. The eventual cropping programme may then be based on optimum use of the interactions between the single cropping variables (Vereijken, 1989b; Vereijken \& Van Loon, 1991). As a 
consequence, optimum product qualities and gross margins may be achieved. For such comprehensive cropping research it is necessary that cropping experts develop a broader view and are more willing to collaborate. More generalists are necessary in research and extension to coordinate such interdisciplinary activities that aim at optimal cropping programs.

\section{Development of prototype systems}

Farming systems mostly have a regional character, based on specific regional circumstances of soil, climate and infrastructure and related possiblities of production, processing and marketing. Therefore, the question of more sustainable farming systems and crop rotations should always be considered within the ecological and social context of the region (Wijnands \& Vereijken, 1992). Because of their multiple objectives integrated and ecosystem-oriented systems call for a balanced approach to this question. In contrast to this, market-oriented farming systems are intensified on purely economic grounds. As a result, major agronomical problems have arisen, especially disrupted nutrient balances (Figure 3) and increased pressure of pests, diseases and weeds. The solution to the latter problems is mainly sought in chemical prevention and control, increasing both costs and adverse effects on nature and environment. Well-considered extensification of systems including rotations and inputs seems the only way out of this complex issue. So, agronomically, economically and environmentally optimal integrated or ecosystem-oriented prototype systems should be developed, preferably on regional experimental farms. (Table 1, step 2.3; details on integrated arable farming in the Netherlands in Table 4, step 2).

Layout of experimental farms. For scientific and policy reasons, it is advisable to elaborate all three basic systems (Table 2). In areas with a wide variation of farms, mixing arable or vegetable crops with animal husbandry, it is advisable to consider a range of systems; from intensive, root-crop dominated rotations to extensive, grassor cereals-dominated rotations. Dependent on farm and soil types, current investments, skills and motivations, farmers then might make an appropriate choice. Of course, an experimental farm should not become too large and unmanageable. On the other hand, the scale between commercial and experimental fields should not exceed $2: 1$, in order to obtain representative results with a minimum of scale-induced arti-

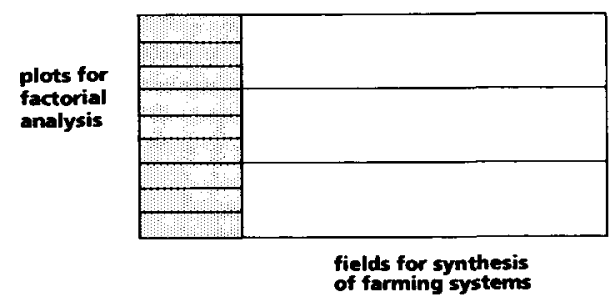

Fig. 4. Development and evaluation of prototype farming systems; spatial separation of analytical and synthetical research to ensure significant and representative results. 


\section{P. VEREIJKEN}

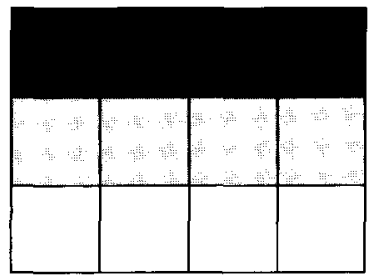

systems with aggregated fields

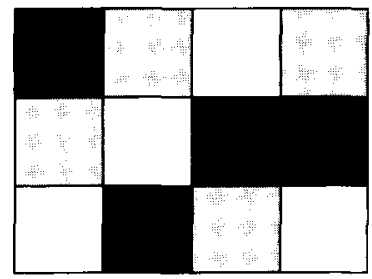

systems with

randomised fields

high input systems

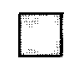

medium inut systems low input systems

Fig. 5. Layout of a farming systems experiment with maximal and minimal chances for a representative agro-ecological identity as a result.

facts. If support of analytical research is needed on the spot, separate areas for factorial analysis could be laid out, in order to avoid disturbance by intensive sampling or large plot experiments (Mikkelsen \& Mikkelsen, 1989) (Figure 4). A farming system can be defined as an agro-ecological unit consisting of a set of steadily interacting and rotating crops and possibly livestock, together with their accompanying (benificial or harmful) flora and fauna. A layout of randomized fields would not contain complete and representative farming systems according to this definition. Only a layout with sufficient aggregation of its fields would permit a farming system to develop an appropriate agro-ecological identity (Figure 5). Since the major objective of an experimental farm is to develop viable prototypes of more sustainable farming systems, the lower mathematical-statistical fitness of such a layout for comparison of farming systems should be accepted. Mathematical-statistically valid comparison and evaluation farming systems is doubtful anyhow for a layout without replicates of systems and management, especially on heterogeneous soils. It can better take place in a next stage with a pilot group of commercial farmers, which would permit a differentation between systems and management/pedoclimate effects.

Programming and coordination of experimental farms. Fundamental and strategic considerations should prevail in the composition of farming and cropping programs in accordance with the long-term objective of research. Personal preferences and objectives of the manager or current market considerations should not play a significant role. To ensure sufficient liberty and continuity of the experiment, a public farm is to be preferred. Moreover, a dynamic approach should be followed. Husbandry programmes need critical reconsideration annually, based on scientific evaluation of the results and new information. Thus, farming systems may improve gradually through good interplay between practice and theory; this calls for a good understanding and clear agreements between management and research, and sufficient delegation of responsibilities to the farm manager and the research coordinator to ensure an effective and flexible policy. The farm manager leads the team of employees and is responsible for an adequate performance of the farming pro- 
grammes. He should have a positive attitude towards research and a creative contribution to systems development. The research coordinator leads the team of researchers and is responsible for the composition and performance of the research programme. He should be an agronomic generalist with a feeling for strategy and the development of systems. It is his task to compose the husbandry programmes in discussion with specialists and the manager. The farm manager is expected to carry them out loyally. If major changes are necessary during the growing season, he should discuss them with the research coordinator. The fine-tuning of the programme is up to the manager, to keep the management effective and flexible. The research programme is to have an analytical and diagnostic character and should aim at steady improvement of the results of each system, based on its quantitative objectives (Table 2). Only if the systems have sufficiently achieved their objectives, is it justified to compare them and to judge them on their feasibility and perspectives. Subsequently, it can be decided whether to test and optimize a new system with a pilot group (Table 1, step 3; details on integrated arable farming in the Netherlands in Table 4, step 3).

\section{Evaluation and optimization of prototype systems}

If research on an experimental farm has produced promising results from an integrated or ecosystem-oriented system, practice and extension may appear very eager to adopt such a system and test it on a large scale. This holds important risks both for the parties and the systems involved. Therefore, it is desirable to continue research in practice through a pilot project. It implies the guidance and evaluation of a group of commercial farmers during their conversion period. By contrast with ordinary study groups, the participants bind themselves by contract to a fundamental and planned approach of the new system.

It is a major goal of such a pilot project to explore the potential impact of a prototype system in practice and to develop safe and generally applicable variants. This demands a fundamental approach to the systems objectives, together with a high input of knowledge and experience and an optimal guidance. A good start for such a project is a course for interested farmers to make them acquainted with the objectives and methods of the system. It is important that farmers and researchers/extension experts gain confidence in each other and the project. As a consequence, the group will select itself through attitude and motivation. Nevertheless, possible financial risks should be sufficiently covered. Based on the experience of the experimental farm and the systems objectives, a package of demands should be formulated and translated into an appropriate farming system for each farm, in consultation with the farmers. As on the experimental farm the system should be carried out in a consistent way and annually adjusted after critical evaluation based on the systems objectives (Table 2). Finally, the research results should be optimized to ecologically acceptable and technically and economically feasible scenarios for regional farming and policy. It could be done by the traditional empirical way or by means of interactive multiplegoal programming. This is a more systematic and quantitative approach still in development, taking into account a regional set of ecological and economical demands (Schans, 1991). 


\section{P. VEREIJKEN}

\section{Introduction of new systems}

The general adoption of a new system requires extension and education (Table 1, step 4; details on integrated arable farming in the Netherlands in Table 4, step 4). A prerequisite is the training of extension specialists and teachers by means of courses. Writing a manual for such courses may enable a structural approach, as revision of subject matter does for agricultural schools. With such an infrastructure farmers can be theoretically and practically schooled in study groups. In the case of conversion of their farms to a more sustainable system, farmers should be supported by appropriate cropping manuals and up-to-date information, e.g. viewdata. For example, in the Netherlands a manual for integrated farming has been dispersed among the 18000 farmers of arable crops (Vereijken \& Wijnands, 1990).

\section{Conclusions and recommendations}

Following the scientific literature, policy plans and the mass media, one has to conclude that there is an urgent need for more sustainable farming systems, with a balanced approach of economical and ecological interests. For the short term, a general conversion to integrated farming systems should be considered as a feasible first step to alleviate the consequences of the ongoing agricultural crisis. However, it cannot change the fact that agro-technology is clearly beyond its optimum, especially in industrial countries, causing degradation of nature and landscape, pollution of the environment and overproduction of food. The latter is a major cause of decreasing incomes and employment in rural areas. The dumping of food surpluses on the world market is even frustrating agriculture in developing countries in a way that cannot be accepted. Therefore, the only long-term solution to this crisis would be advanced ecosystem-oriented farming systems, principally carried by a strong home market with quality labels and premium prices to ensure sufficient management achievements and economic margins. Fortunately, an increasing number of consumers seem ready to accept this. Agricultural research should consider the challenge, broaden its scope and shift to a comprehensive and more sustainable approach to farming system development, as described in this paper.

\section{References}

Allen, P. \& D. van Dusen (Eds), 1988. Global perspectives on agroecology and sustainable agricultural systems. Proceedings of the Sixth International Conference of International Federation Organic Agriculture Movements." Agroecology Program, University of California, Santa Cruz, $721 \mathrm{pp}$.

Daamen, R.A., F.G. Wijnands \& G. van der Vliet, 1989. Epidemics of diseases and pests of winter wheat at different levels of agrochemical input. Journal of Phytopathology 125:305-319.

Edwards, C.A., R. Lal, P. Madden, R.H. Miller \& G. House (Eds), 1990. Sustainable agricultural systems. Soil and Water Conservation Society, Iowa, $696 \mathrm{pp}$.

El Titi, A., 1989. Farming systems research at Lautenbach. In: P. Vereijken \& D.J. Royle (Eds), Current status of integrated arable farming systems research in Western Europe, IOBC/WPRS Bulletin 1989/XII/5, Wageningen, p. 21-36. 


\section{METHODIC WAY TO MORE SUSTAINABLE FARMING}

El Titi, A. \& H. Landes, 1990. Integrated farming system of Lautenbach. In: C.A. Edwards, R. Lal, P. Madden, R.H. Miller \& G. House (Eds), Sustainable agricultural systems, p. 265-286.. Soil and Water Conservation Society, Iowa.

Haeni, F., 1989. The third way, a research project in ecologically orientated farming systems in Switzerland. In: P. Vereijken \& D.J. Royle (Eds), Current status of integrated arable farming systems research in Western Europe. IOBC/WPRS Bulletin 1989/XII/5, Wageningen, p. 51-66.

Jordan, V.W.L., G.R. Stinchcombe \& J.A. Hutcheon, 1989. Fungicide and nitrogen interactions in relation to the improvement of disease control and yield in winter barley. Plant Pathology 38:26-34.

Mikkelsen, G. \& S. Mikkelsen, 1989. Start of farming systems research in Denmark. In: P. Vereijken \& D.J. Royle (Eds), Current status of integrated arable farming systems research in Western Europe. IOBC/WPRS Bulletin 1989/XII/5, Wageningen, p. 6-15.

National Research Council of USA, 1989. Alternative agriculture. Report of the committee on the role of alternative farming methods in modern production agriculture. NRC, Washington, D.C., $448 \mathrm{pp}$.

Schans, J., 1991. Optimal potato production systems with respect to economic and ecological goals. Agricultural Systems 37:387-397.

Vereijken, P. \& D.J. Royle (Eds), 1989. Current status of integrated arable farming systems research in Western Europe. IOBC/WPRS Bulletin 1989/XII/5, Wageningen, 76 pp.

Vereijken, P., 1989a. Research on integrated arable farming and organic mixed farming in the Netherlands. In: P. Vereijken \& D.J. Royle (Eds), Current status of integrated arable farming systems research in Western Europe. IOBC/WPRS Bulletin 1989/XII/5, Wageningen, p. 41-50.

Vereijken, P., 1989b. Experimental systems of integrated and organic wheat production. Agricultural Systems 30:187-197.

Vereijken, P., 1989c. From integrated control to integrated farming, an experimental approach. Agriculture, Ecosystems and Environment 26:37-43.

Vereijken, P., 1990a. Research on integrated arable farming and organic mixed farming in the Netherlands. In: C.A. Edwards, R. Lal, P. Madden, R.H. Miller \& G. House (Eds), Sustainable agricultural systems, p. 287-298. Soil and Water Conservation Society, Iowa.

Vereijken, P., 1990b. Integrated nutrient management for arable farming. La Recherche Agronomique en Suisse 29:359-367. (Also in German, p. 367-371).

Vereijken, P. \& C.D. van Loon, 1991. A strategy for integrated low-input potato production. Potato Research 34:57-66.

Vereijken, P. \& F.G. Wijnands, 1990. Integrated agriculture into practice; strategy for farm and environment. (In Dutch). Publication No. 50, Research Station for Arable Farming and Field Production of Vegetables, Lelystad, $85 \mathrm{pp}$.

Wijnands, F.G., 1992. Evaluation and introduction of integrated arable farming in practice. Netherlands Journal of Agricultural Science 40:239-249.

Wijnands, F.G. \& P. Vereijken, 1992. Region-wise development of prototypes of integrated arable farming and outdoor horticulture. Netherlands Journal of Agricultural Science 40:225-238.

Zadoks, J.C., 1988. EPIPRE: Research, development and application of an integrated disease and pest management system for wheat. In: D.J. Royle, R. Rabbinge \& C.R. Fluckiger, (Eds), Models in integrated crop protection. IOBC-WPRS Bulletin 1988/XI/2, Wageningen, p. 82-91. 